\title{
Emergency airway management in a Singapore centre: A registry study
}

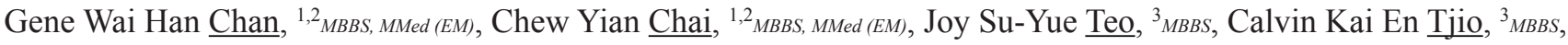
Mui Teng Chua, ${ }^{1,2}$ MBBS, MMed (EM), MPH, Calvin A Brown III, ${ }^{* 4,5}{ }_{\text {MD, FAAEM }}$

\begin{abstract}
Introduction: Intubations in the emergency department (ED) are often performed immediately without the benefit of pre-selection or the ability to defer. Multicentre observational data provide a framework for understanding emergency airway management but regional practice variation may exist. We aim to describe the intubation indications, prevalence of difficult airway features, peri-intubation adverse events and intubator characteristics in the ED of the National University Hospital, Singapore.

Methods: We conducted a prospective observational study over a period of 31 months from 1 March 2016 to 28 September 2018. Information regarding each intubation attempt, such as indications for intubation, airway assessment, intubation techniques used, peri-intubation adverse events, and clinical outcomes, was collected and described.

Results: There were 669 patients, with male predominance $(67.3 \%, 450 / 669)$ and mean age of 60.9 years (standard deviation [SD] 18.1). Of these, $25.6 \%$ were obese or grossly obese and majority were intubated due to medical indications (84.8\%, 567/669). Emergency physicians' initial impression of difficult airway correlated with a higher grade of glottis view on laryngoscopy. First-pass intubation success rate was $86.5 \%$, with hypoxia $(11.2 \%, 75 / 669)$ and hypotension $(3.7 \%, 25 / 669)$ reported as the two most common adverse events. Majority was rapid sequence intubation $(67.3 \%, 450 / 669)$ and the device used was most frequently a video laryngoscope $(75.6 \%, 506 / 669)$. More than half of the intubations were performed by postgraduate clinicians in year 5 and above, clinical fellows or attending physicians.

Conclusion: In our centre, the majority of emergency intubations were performed for medical indications by senior doctors utilising rapid sequence intubation and video laryngoscopy with good ffirst-attempt success.
\end{abstract}

Ann Acad Med Singap 2021;50:42-51

Keywords: Difficult airway, emergency services, intubation, peri-intubation adverse events, rapid sequence induction

\section{INTRODUCTION}

Emergency airways often present with little warning, and the need for airway management is necessary for a successful resuscitation. This is in contrast to most intubations performed in the operating room (OR). Additionally, difficult airways are more prevalent in emergency department (ED) populations due to acute conditions such as blunt and penetrating trauma, burns, decompensated physiology and various pathological causes of airway obstruction., ${ }^{1,2}$ The emergency physician needs to understand the current practice, expectations and anticipated outcomes for emergency department intubations.

Complications faced during ED intubations are numerous; ${ }^{3-5}$ the correlation between repeated intubation attempts and the increased frequency of complications have been previously reported. ${ }^{6-8}$ As such, minimising the number of repeated intubation attempts may help reduce

\footnotetext{
${ }^{1}$ Emergency Medicine Department, National University Hospital, National University Health System, Singapore

${ }^{2}$ Department of Surgery, Yong Loo Lin School of Medicine, National University of Singapore, Singapore

${ }^{3}$ Ministry of Health Holdings Pte Ltd, Singapore

${ }^{4}$ Department of Emergency Medicine, Brigham and Women's Hospital, Boston, MA, United States

${ }^{5}$ Harvard Medical School, Boston, MA, United States

Correspondence: Dr Mui Teng Chua, 9 Lower Kent Ridge Road, Level 4, Emergency Medicine Department Office, Singapore 119085.

Email: mui_teng_chua@nuhs.edu.sg

"On behalf of the National Emergency Airway Registry (NEAR) investigators
} 
the number of adverse events. Understanding the epidemiology of ED patients who require intubation, techniques used and success rates could allow emergency physicians to better equip themselves in airway management.

This study aims to describe the indications, methods, devices used, intubator characteristics, prevalence of difficult airway features, peri-intubation adverse events and outcomes for ED intubations at the National University Hospital (NUH), Singapore.

\section{METHODS}

\section{Study design}

This was a prospective observational study conducted at the ED of NUH over a period of 31 months from 1 March 2016 to 28 September 2018. Ethics approval was obtained for waiver of consent from the National Healthcare Group, Domain Specific Review Board (DSRB reference number: 2019/01154). The study was part of the National Emergency Airway Registry (NEAR). ${ }^{3,9-11}$

\section{Study setting and eligibility criteria}

The study is based in NUH, a tertiary academic hospital with over 120,000 ED visits yearly, of which about $47 \%$ of the cases require urgent $(42.5 \%)$ or immediate $(4.5 \%)$ care. Adult patients aged 21 years and above requiring intubation were eligible for inclusion. Patients who were under 21 years old were excluded from this study.

\section{Variables collected}

The variables collected include patient demographics, indications for intubation, pre-intubation haemodynamic status, airway assessment, preoxygenation methods, number of intubation attempts, equipment and medications used for each attempt, vital signs, confirmation of tube placement, level of intubator training, preintubation adverse events, and patient disposition. Body habitus was estimated visually by attending clinicians' gestalt and classified as very thin, thin, normal, obese and grossly obese. Data were collected using a standardised data collection form which was completed by the intubating physician following each intubation. Where possible, research assistants approached attending physicians for missing data to complete the forms. The data were then entered into StudyTRAX (ScienceTRAX, Macon, US), an online data entry portal with site-specific login credentials. At least $90 \%$ reporting compliance was required to maintain active data in the registry.

\section{Statistical analysis}

Results were analysed using Stata version 14 (StataCorp LP, College Station, US). Descriptive data were described in proportions. Categorical data were analysed using chi-square test or Fisher's exact test, where appropriate. Odds ratios (OR) for correlation of glottic grade with physicians' impression of difficult airway were calculated using multiple logistic regression with $95 \%$ confidence intervals (CIs) and $P$ values reported. A $P$ value $<0.05$ was considered statistically significant.

\section{RESULTS}

Over the 31-month period, a total of 669 patients were included, with male predominance $(67.3 \%$, $450 / 669$ ) and mean age of 60.9 years (standard deviation [SD] 18.1) (Table 1). Of these patients, $25.6 \%$ were obese or grossly obese, and majority were intubated due to medical indications $(84.8 \%, 567 / 669)$. Overall, the 2 most frequent indications for intubations were cardiac arrest $(31.1 \%, 208 / 669)$ and non-traumatic intracranial haemorrhage $(13.6 \%, 91 / 669)$; other indications are illustrated in Table 1.

There were $38.6 \%(258 / 669)$ of patients with an initial impression of airway difficulty; $22.3 \%$ (149/669) had neck immobility, 6\% (40/669) had facial trauma and $26.3 \%(176 / 669)$ had blood in airway. Of those assessed, 42.1\% (90/214) of patients had Mallampati Class 3 or $4,39.5 \%(156 / 395)$ had reduced mouth opening and $46.7 \%(189 / 405)$ had decreased thyromental distance ( 1 or 2 fingers). The airway features of obese and grossly obese patients are illustrated in Table 2. There were $62.7 \%(96 / 153)$ of obese and $94.4 \%(17 / 18)$ of grossly obese patients with an initial impression of airway difficulty. Among those who were examined for external airway features, $56.6 \%$ of obese and $87.5 \%$ of grossly obese had Mallampati classification of 3 and above; $45.5 \%$ of obese and $90.9 \%$ of grossly obese had reduced mouth opening.

For patients who were intubated with a video laryngoscope, all clinical predictors of an anatomically difficult airway (i.e. Mallampati, presence of reduced mouth opening, etc.) apart from facial trauma showed good correlation with glottic exposure (Table 3). Emergency physicians' initial impression of difficult airway also correlated with a worse Cormack and Lehane (CL) grade view after adjusting for type of laryngoscope used (direct versus video laryngoscope) (Table 4).

Majority of the patients in our ED underwent rapid sequence intubation (RSI) with induction and paralysis, most commonly with etomidate and succinylcholine 
Table 1. Demographics $(\mathrm{N}=669)$

\begin{tabular}{|c|c|}
\hline Variables & n $(\%)$ \\
\hline Male gender & $450(67.3)$ \\
\hline Age in years, mean (SD) & $60.9(18.1)$ \\
\hline \multicolumn{2}{|l|}{ Habitus, by visual estimation } \\
\hline Very thin & $28(4.2)$ \\
\hline Thin & $142(21.2)$ \\
\hline Normal & $328(49.0)$ \\
\hline Obese & $153(22.9)$ \\
\hline Grossly obese & $18(2.7)$ \\
\hline \multicolumn{2}{|l|}{ Indication for intubation } \\
\hline Medical & $567(84.8)$ \\
\hline Trauma & $102(15.2)$ \\
\hline Top 10 trauma indications & $n=102$ \\
\hline Head injury with haemorrhage & $30(29.4)$ \\
\hline Polytrauma & $23(22.5)$ \\
\hline Facial trauma & $16(15.7)$ \\
\hline Traumatic arrest & $12(11.8)$ \\
\hline Head injury without haemorrhage & $9(8.8)$ \\
\hline Chest trauma & $4(3.9)$ \\
\hline Abdominal trauma & $3(2.9)$ \\
\hline Combative/agitated & $2(2.0)$ \\
\hline Haemorrhagic shock & $2(2.0)$ \\
\hline Neck trauma & $1(1.0)$ \\
\hline Top 10 medical indications & $\mathrm{n}=567^{\mathrm{a}}$ \\
\hline Cardiac arrest & $208(36.7)$ \\
\hline Intracranial haemorrhage (non-traumatic) & $91(16.1)$ \\
\hline Pneumonia & $57(10.1)$ \\
\hline Septic shock & $44(7.8)$ \\
\hline Congestive cardiac failure & $35(6.2)$ \\
\hline Cerebrovascular accident & $22(3.9)$ \\
\hline Gastrointestinal bleed & $17(3.0)$ \\
\hline Seizures & $17(3.0)$ \\
\hline Acute myocardial infarction & $16(2.8)$ \\
\hline Non-overdose altered mental state & $16(2.8)$ \\
\hline \multicolumn{2}{|l|}{ Patient coding } \\
\hline No & $446(66.7)$ \\
\hline Yes & $223(33.3)$ \\
\hline Sepsis suspected & $119(17.8)$ \\
\hline Elevated ICP suspected & $172(25.7)$ \\
\hline
\end{tabular}

ICP: intracranial pressure; SD: standard deviation

a Total number of patients who were intubated based on medical indications.
(Table 5). The most common device used was a C-MAC video laryngoscope (72.6\%, 486/669) (Table $5)$. For patients who were still breathing spontaneously and where the need for intubation was not immediate, $96.1 \%$ (347/361) achieved a pre-oxygenation time of more than 3 minutes. Among these patients, 83.9\% $(303 / 361)$ had nasal cannulae in place during the apnoeic phase. Overall, first-pass success rate at intubation was $86.5 \%$, and was not significantly different between video and direct laryngoscopy. Postgraduate year 5 trainees, fellows and attending physicians performed more than half of the intubations. Among obese and grossly obese patients, first-pass success was $83.7 \%(128 / 153)$ and $66.7 \%(12 / 18)$, respectively and more than $60 \%$ of the first attempts were performed by postgraduate year 5 and above (Table 2). Majority of obese patients $(58.2 \%$, 89/152) had CL grade 1 glottic view while most of the grossly obese only had a grade 2 view $(44.4 \%, 8 / 18)$ (Table 2). The most commonly encountered adverse events during intubation were hypoxia and hypotension.

Post-intubation, the most frequently used sedation and analgesic medications were propofol and fentanyl (Table 6). The median lowest $\mathrm{SpO}_{2}$ achieved for patients with desaturation was 79\% (IQR 70-85). Disposition outcomes after intubation are detailed in Table 6.

\section{DISCUSSION}

Airway management is an essential skill for emergency physicians. Difficult airway management is a norm rather than an exception due to widespread obesity and acquired difficult airway characteristics that come with an ageing patient population. There is a great prevalence of obesity worldwide, ${ }^{12}$ with estimates that at least a third of all adults are either overweight or obese. ${ }^{13}$ In comparison with other studies, our study cohort had a higher proportion of obese patients $(25.6 \%) .{ }^{14}$ Obesity has been linked with lower success rates on first intubation attempt, as well as higher risks of adverse events. ${ }^{15}$ Difficult airways are more common in obese patients because of soft tissue causing airway obstruction, leading to difficulty with bag-valve mask ventilation, distortion of anatomy, and difficulty aligning the axis due to back adiposity. It is also associated with reduced cardiovascular reserves, respiratory reserves, and thus increases the risk of adverse outcomes such as rapid oxygen desaturation. ${ }^{16}$ It is reassuring that first-pass success rate is high in our obese and grossly obese patients. The exact reason for good success rates is hard to determine from our observational data but is likely a result of good preparation, positioning (such as with troop pillow), high usage of video laryngoscope and operator experience. With these measures, we were 
Table 2. Airway features and first-pass success rates of obese and grossly obese patients

\begin{tabular}{|c|c|c|}
\hline \multirow[t]{2}{*}{ Variables } & \multicolumn{2}{|c|}{ Habitus $^{\mathrm{a}}$} \\
\hline & Obese $(n=153)$ & Grossly obese $(n=18)$ \\
\hline Initial impression of airway difficulty & $96(62.8)$ & $17(94.4)$ \\
\hline Presence of neck immobility & $26(16.7)$ & $7(38.9)$ \\
\hline Mallampati $(\mathrm{n}=61)^{\mathrm{b}}$ & $\mathrm{n}=\mathbf{5 3}$ & $n=8$ \\
\hline Class 1 & $9(17.0)$ & 0 \\
\hline Class 3 & $25(47.2)$ & $3(37.5)$ \\
\hline Class 4 & $5(9.4)$ & $4(50.0)$ \\
\hline Mouth opening $(n=108)^{b}$ & $\mathbf{n}=\mathbf{9 7}$ & $\mathrm{n}=11$ \\
\hline Normal & $53(54.6)$ & $1(9.1)$ \\
\hline Reduced (1 to 2 FBs) & $44(45.4)$ & $10(90.9)$ \\
\hline 1 finger & $5(4.6)$ & $2(18.2)$ \\
\hline 2 fingers & $58(53.2)$ & $5(45.5)$ \\
\hline 3 fingers & $46(42.2)$ & $4(36.4)$ \\
\hline $4+$ fingers & 0 & 0 \\
\hline Obstruction present & $8(5.2)$ & $3(16.7)$ \\
\hline Facial trauma & $5(3.3)$ & $1(5.6)$ \\
\hline Blood in airway & $33(21.6)$ & $7(38.9)$ \\
\hline \multicolumn{3}{|l|}{ Glottic view } \\
\hline Grade 1 (full view) & $89(58.2)$ & $4(22.2)$ \\
\hline Grade 2 (partial view) & $46(30.1)$ & $8(44.4)$ \\
\hline Grade 3 (epiglottis only) & $12(7.8)$ & $5(27.8)$ \\
\hline Grade 4 (no view) & $6(3.9)$ & $1(5.6)$ \\
\hline \multicolumn{3}{|l|}{ Intubator level } \\
\hline PGY 1 & $5(3.3)$ & 0 \\
\hline PGY 2 & $25(16.3)$ & $2(11.1)$ \\
\hline PGY 3 & $8(5.2)$ & $1(5.6)$ \\
\hline PGY 4 & $23(15.0)$ & $1(5.6)$ \\
\hline $\mathrm{PGY} \geq 5$ or fellow & $67(43.8)$ & $6(33.3)$ \\
\hline Attending & $25(16.3)$ & $8(44.4)$ \\
\hline
\end{tabular}

FB: fingerbreadth; PGY: postgraduate year

${ }^{\text {a }}$ Habitus estimated visually by attending clinicians.

${ }^{\mathrm{b}}$ Not assessed in the rest of the patients.

able to achieve a grade 1 or 2 glottic view in majority of these patients. Hence, although the increased prevalence of obesity with its associated risks and complications may pose challenges in airway management for emergency physicians, ${ }^{15,17}$ appropriate steps taken can still allow an adequate first-pass success rate.

Another cause for concern in airway management is the increasing number of geriatric patients seen in the ED. Our study cohort had a median age of 60.9 years, which is higher than that of other studies. ${ }^{18}$ This is congruent with the increasing ageing population seen in Singapore's healthcare system. ${ }^{19}$ Ageing is associated with changes in the airway manifested through edentulous mouth, glottic muscle atrophy and reduced neck mobility, which increases the difficulty of ventilation and intubation. ${ }^{20}$ The higher prevalence of comorbidities like chronic obstructive pulmonary disease and gastroesophageal reflux disease increases the risk of aspiration pneumonia. ${ }^{20}$ In addition, the elderly are more prone to adverse events such as myocardial ischaemia and hypotension due to labile blood pressure responses during induction,,$^{20}$ and varying types and dosages of induction 


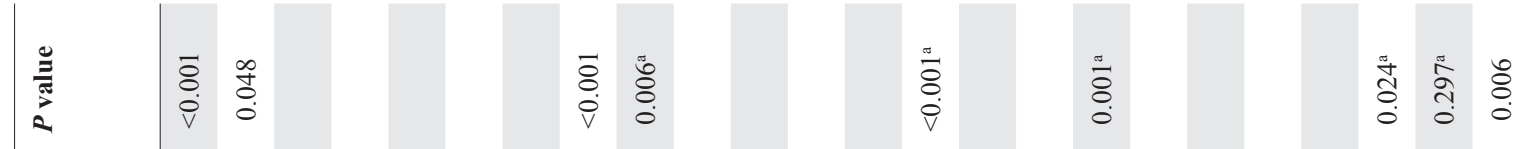

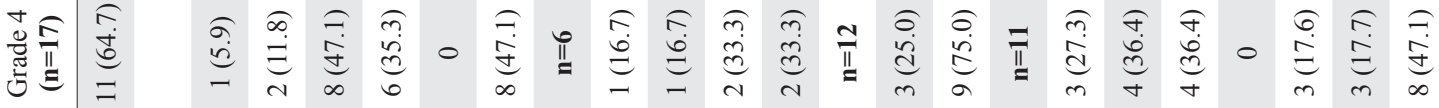

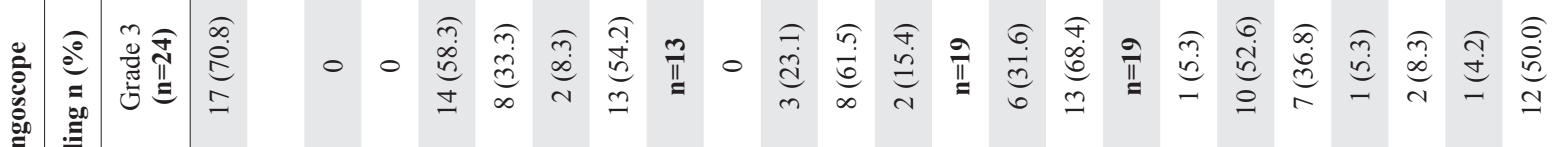

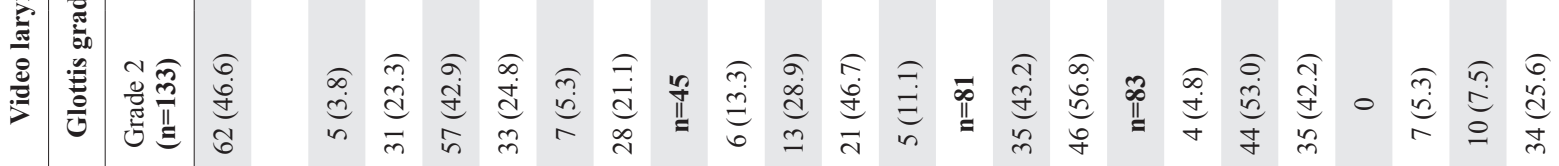

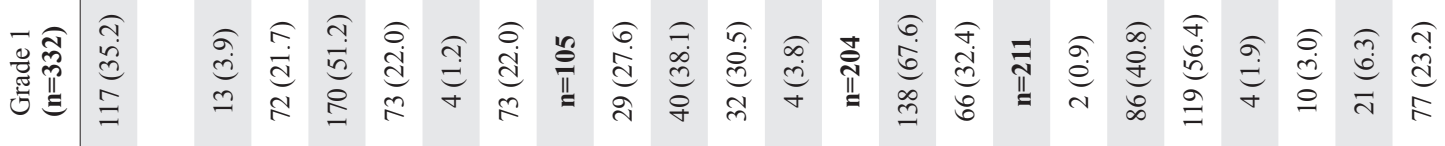

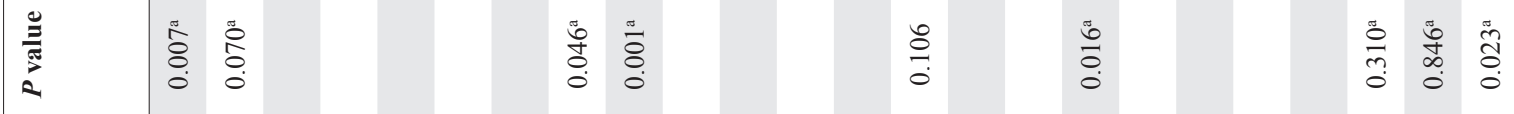

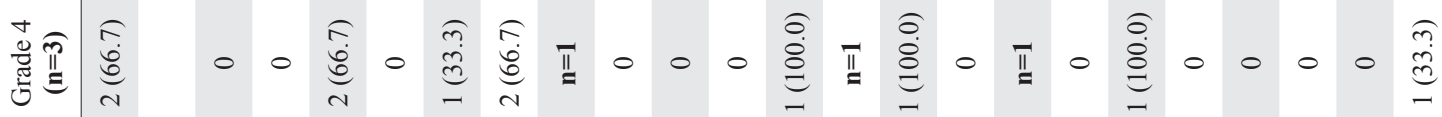

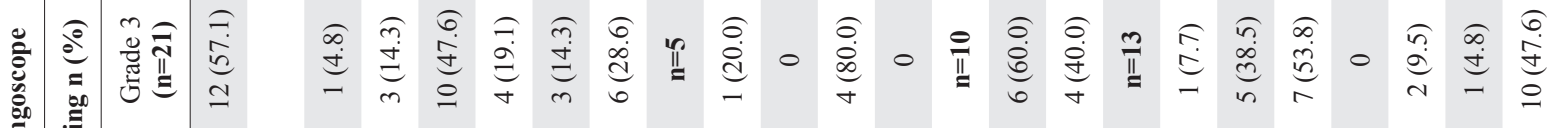

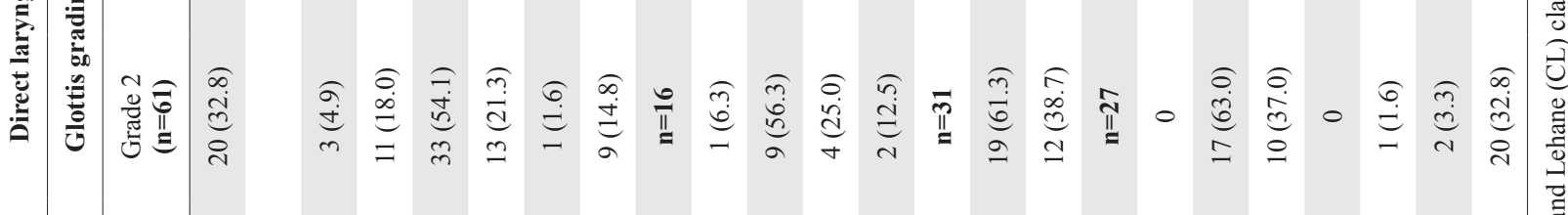

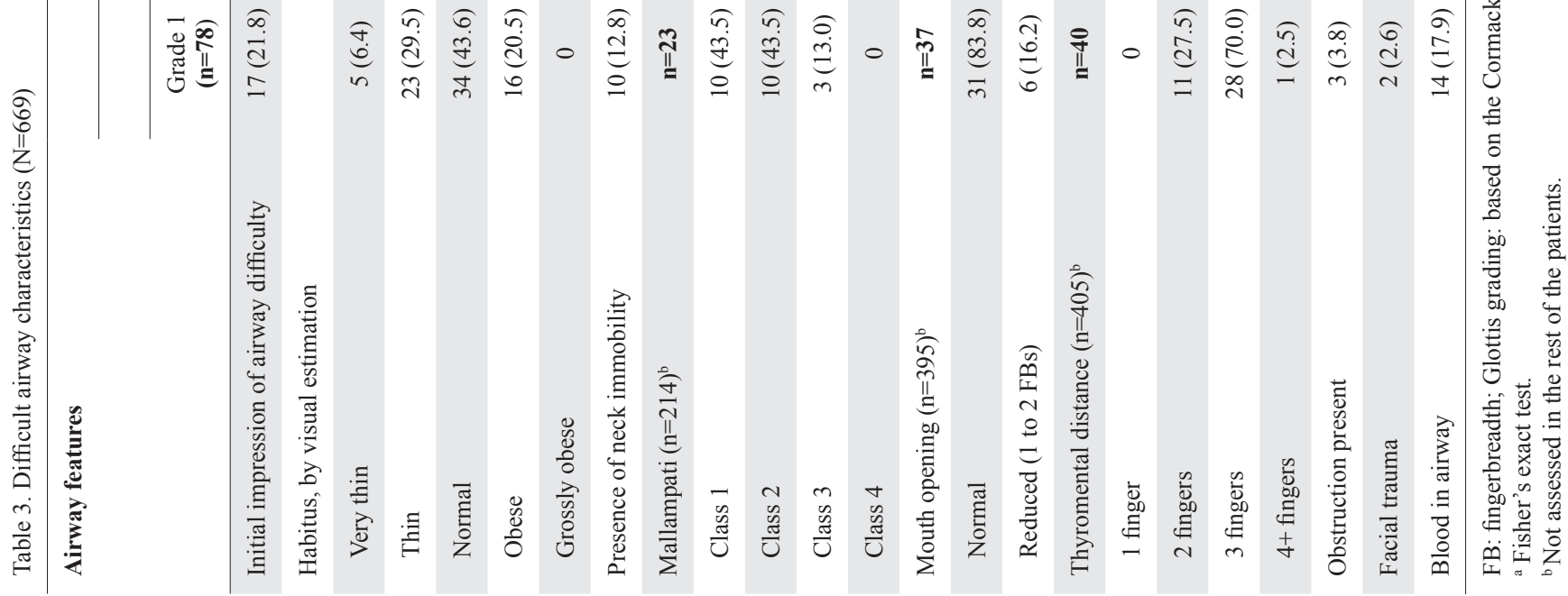


Table 4. Odds ratios of impression of airway difficulty with glottic grading $(\mathrm{N}=669)$

\begin{tabular}{lccc}
\hline Variables & $\begin{array}{c}\text { Presence of airway difficulty on initial } \\
\text { impression (OR) }\end{array}$ & 95\% CI & $P$ value \\
\hline Grade of glottic view & Reference & & \\
\hline Grade 1 (full view) & 1.63 & 1.14 to 2.34 & 0.007 \\
\hline Grade 2 (partial view) & 4.52 & 2.32 to 8.81 & $<0.001$ \\
\hline Grade 3 (epiglottis only) & 3.79 & 1.47 to 9.79 & 0.006 \\
\hline Grade 4 (no view) & & & \\
\hline Type of device & Reference & & 1.23 to 2.73 \\
\hline Direct laryngoscope & 1.84 & 0.003 \\
\hline Video laryngoscope & & & \\
\hline
\end{tabular}

CI: confidence interval; OR: odds ratio

Table 5. Intubation attempts $(\mathrm{N}=669)$

\begin{tabular}{|c|c|c|c|c|}
\hline Variables & $\begin{array}{c}\text { Attempt } 1 \\
(n=669)\end{array}$ & $\begin{array}{c}\text { Attempt } 2 \\
(n=90)\end{array}$ & $\begin{array}{c}\text { Attempt } 3 \\
(n=15)^{\mathrm{a}}\end{array}$ & $\begin{array}{c}\text { Attempt } 4 \\
(n=5)^{b}\end{array}$ \\
\hline Success & $579(86.5)$ & $74(82.2)$ & $9(60.0)$ & $3(60.0)^{c}$ \\
\hline \multicolumn{5}{|l|}{ Methods of intubation } \\
\hline Sedation and paralysis & $450(67.3)$ & $2(2.2)$ & $2(13.3)$ & 0 \\
\hline Sedation only & $2(0.3)$ & 0 & 0 & 0 \\
\hline Paralysis only & $13(1.9)$ & $5(5.6)$ & 0 & $1(20.0)$ \\
\hline Topical anaesthesia & $1(0.2)$ & 0 & 0 & $1(20.0)$ \\
\hline No meds & $203(30.3)$ & $83(92.2)$ & 0 & 0 \\
\hline Induction agent & $n=452$ & $\mathrm{n}=\mathbf{2}$ & $\mathbf{n}=\mathbf{2}$ & \\
\hline Etomidate & $319(70.6)$ & $1(50)$ & $2(100.0)$ & 0 \\
\hline Ketamine & $85(18.8)$ & 0 & 0 & 0 \\
\hline Midazolam & $2(0.4)$ & 0 & 0 & 0 \\
\hline Propofol & $46(10.2)$ & $1(50)$ & 0 & 0 \\
\hline Paralysis agent & $n=463$ & $\mathrm{n}=7$ & $\mathrm{n}=\mathbf{2}$ & $\mathrm{n}=\mathbf{1}$ \\
\hline Rocuronium & $36(7.8)$ & $1(14.3)$ & $1(50.0)$ & 0 \\
\hline Succinylcholine & $427(92.2)$ & $6(85.7)$ & $1(50.0)$ & $1(100.0)$ \\
\hline \multicolumn{5}{|l|}{ Intubator specialty ${ }^{\mathrm{d}}$} \\
\hline Emergency medicine & $475(71.0)$ & $86(95.6)$ & $12(80.0)$ & $2(40.0)$ \\
\hline Anaesthesia & 0 & $2(2.2)$ & $3(20.0)$ & $3(60.0)$ \\
\hline Paediatrics & $2(0.3)$ & 0 & 0 & 0 \\
\hline General surgery & $17(2.5)$ & $1(1.1)$ & 0 & 0 \\
\hline Internal medicine & $100(15.0)$ & 0 & 0 & 0 \\
\hline Family medicine & $73(10.9)$ & 0 & 0 & 0 \\
\hline Physician assistant & $1(0.15)$ & 0 & 0 & 0 \\
\hline Paediatric emergency medicine & $1(0.15)$ & $1(1.1)$ & 0 & 0 \\
\hline Intubator level & $n=668$ & & & \\
\hline PGY 1 & $14(2.1)$ & 0 & 0 & 0 \\
\hline PGY 2 & $128(19.2)$ & 0 & 0 & 0 \\
\hline
\end{tabular}


Table 5. Intubation attempts $(\mathrm{N}=669)$ (Cont'd)

\begin{tabular}{|c|c|c|c|c|}
\hline Variables & $\begin{array}{c}\text { Attempt } 1 \\
(n=669)\end{array}$ & $\begin{array}{c}\text { Attempt } 2 \\
(n=90)\end{array}$ & $\begin{array}{l}\text { Attempt } 3 \\
(n=15)^{\mathrm{a}}\end{array}$ & $\begin{array}{c}\text { Attempt } 4 \\
(n=5)^{b}\end{array}$ \\
\hline PGY 3 & $62(9.3)$ & 0 & 0 & 0 \\
\hline PGY 4 & $95(14.2)$ & $6(6.7)$ & 0 & 0 \\
\hline $\mathrm{PGY} \geq 5$ or fellow & $265(39.7)$ & $27(30.0)$ & $3(20.0)$ & $2(40.0)$ \\
\hline Attending & $104(15.5)$ & $57(63.3)$ & $12(80.0)$ & $3(60.0)$ \\
\hline \multicolumn{5}{|l|}{ Position during intubation } \\
\hline C-spine extension only & $69(10.3)$ & $9(10.0)$ & $1(6.6)$ & 0 \\
\hline Full sniffing position & $406(60.7)$ & $46(51.1)$ & $7(46.7)$ & $1(20.0)$ \\
\hline Neutral C-spine & $190(28.4)$ & $34(37.8)$ & $7(46.7)$ & $4(80.0)$ \\
\hline Ramped position & $2(0.3)$ & 0 & 0 & 0 \\
\hline \multicolumn{5}{|l|}{ Device used } \\
\hline Clarus video system & $1(0.1)$ & 0 & 0 & 0 \\
\hline C-MAC standard blade & $474(70.9)$ & $51(56.7)$ & $5(33.3)$ & $1(20.0)$ \\
\hline C-MAC D blade & $12(1.8)$ & $6(6.7)$ & $1(6.7)$ & $1(20.0)$ \\
\hline C-MAC straight blade & 0 & $2(2.2)$ & 0 & 0 \\
\hline Direct laryngoscope (MacIntosh) & $163(24.4)$ & $25(27.8)$ & $6(40.0)$ & 0 \\
\hline Fingers/digital & 0 & $1(1.1)$ & 0 & 0 \\
\hline McGrath video laryngoscope & $19(2.8)$ & $4(4.4)$ & $2(13.3)$ & $2(40.0)$ \\
\hline Surgical cric set & 0 & $1(1.1)$ & $1(6.7)$ & $1(20.0)$ \\
\hline BURP used & $295(44.1)$ & $53(58.9)$ & $11(73.3)$ & $4(80.0)$ \\
\hline Oral & $669(100)$ & $88(97.8)$ & $14(93.3)$ & $5(100.0)$ \\
\hline Surgical & 0 & $2(2.2)$ & $1(6.7)$ & 0 \\
\hline Number of patients with adverse events during intubation & $92(13.8)$ & $9(10.0)$ & $2(13.3)$ & $2(40.0)$ \\
\hline Type of adverse event ${ }^{\mathrm{e}}$ & $\mathrm{n}=92$ & $\mathbf{n}=9$ & $\mathbf{n}=\mathbf{2}$ & $\mathbf{n}=\mathbf{2}$ \\
\hline Hypoxia & $64(69.6)$ & $8(88.9)$ & $1(50.0)$ & $2(100.0)$ \\
\hline Hypotension & $21(22.8)$ & $2(20.0)$ & $1(50.0)$ & 0 \\
\hline Cardiac arrest & $7(7.6)$ & 0 & 0 & 0 \\
\hline Vomiting & $4(4.3)$ & 0 & 0 & 0 \\
\hline Bradycardia & $2(2.2)$ & 0 & 0 & 0 \\
\hline Dental trauma & $3(3.3)$ & 0 & 0 & $1(50.0)$ \\
\hline Main stem intubation & $2(2.2)$ & 0 & 0 & 0 \\
\hline Tachydysrhythmia & $2(2.2)$ & 0 & 0 & 0 \\
\hline Laryngospasm & $1(1.1)$ & 0 & 0 & 0 \\
\hline Pneumothorax & 0 & $1(11.1)$ & 0 & 0 \\
\hline
\end{tabular}

BURP: backward, upward and right pressure; C-spine: cervical spine; cric: cricothyroidotomy; PGY: postgraduate year

${ }^{a}$ One patient died hence there was no additional attempt.

${ }^{\mathrm{b}}$ One patient had extraglottic device inserted.

' Two patients with failed attempts; 1 had extraglottic device inserted, 1 had intubation taken over by anaesthesia team.

${ }^{\mathrm{d}}$ The intubations done by intubators from paediatric emergency medicine and paediatrics were by trainees in these residency training programmes who had rotated to the adult emergency department for an elective posting.

${ }^{\mathrm{e}}$ Proportions calculated using number of patients with adverse events as denominator; total percentage is more than $100 \%$ as each patient may have more than one adverse event. 
Table 6. Outcomes and subsequent management $(\mathrm{N}=669)$

\begin{tabular}{|c|c|}
\hline Variables & n (\%) \\
\hline \multicolumn{2}{|l|}{ Confirmation of placement } \\
\hline Qualitative $\mathrm{ETCO}_{2}$ & $451(67.4)$ \\
\hline Quantitative $\mathrm{ETCO}_{2}$ & $181(27.1)$ \\
\hline Auscultation of lungs & $657(98.2)$ \\
\hline Condensation in tube & $358(53.5)$ \\
\hline Bedside ultrasound & $12(1.8)$ \\
\hline Bougie & $35(5.2)$ \\
\hline Peri-intubation desaturation $^{a}(n=446)$ & $57(12.8)$ \\
\hline Lowest $\mathrm{SpO}_{2}$ during desaturation, median (IQR) & $79(70-85)$ \\
\hline Hypotensive 15 mins after intubation ${ }^{\mathrm{a}}(\mathrm{n}=446)$ & $61(13.7)$ \\
\hline Lowest systolic blood pressure in mmHg, median (IQR) & $80(66-87)$ \\
\hline Treatment required for hypotensive episodes $(n=61)$ & $45(73.8)$ \\
\hline \multicolumn{2}{|l|}{ Disposition } \\
\hline $\mathrm{ICU}$ & $375(56.0)$ \\
\hline Died in ED (unrelated to failed airway) & $156(23.3)$ \\
\hline OT & $94(14.1)$ \\
\hline Extubated in ED & $3(0.5)$ \\
\hline Transferred & $41(6.1)$ \\
\hline \multicolumn{2}{|l|}{ Post-intubation medications } \\
\hline Propofol & $355(53.1)$ \\
\hline Midazolam & $6(0.9)$ \\
\hline Diazepam & $2(0.3)$ \\
\hline Ketamine & $18(2.7)$ \\
\hline Fentanyl & $268(40.1)$ \\
\hline Paralytic & $40(6.0)$ \\
\hline Pressor & $58(8.7)$ \\
\hline Morphine & $2(0.3)$ \\
\hline No medication & $196(29.3)$ \\
\hline
\end{tabular}

ED: emergency department; $\mathrm{ETCO}_{2}$ : end-tidal carbon dioxide; ICU: intensive care unit; IQR: interquartile range; OT: operating theatre; $\mathrm{SpO}_{2}$ : peripheral capillary oxygen saturation

${ }^{a}$ Information available in 446 patients.

agents that may be required compared to those for the younger patients. In view of such differences, management of emergency airways in the elderly population should be individualised and tailored accordingly.

Apart from obesity and ageing, other airway features such as a higher Mallampati score, presence of airway obstruction, reduced mouth opening, thyromental distance and neck mobility can also complicate airway management. In our study, these key features of initial airway assessment directly corresponded to the severity of the glottis grading in each patient. Emergency physicians' initial impression of difficult airway were also consistent with actual glottic grading. Nevertheless, the prediction of airway difficulty was not $100 \%$ accurate and emergency physicians should still be sufficiently prepared to deal with a challenging intubation. Although it is well documented that the presence of facial trauma is associated with difficult airway, ${ }^{21}$ it is interesting to note that the patients with facial trauma in this study were not significantly associated with a higher glottic grade. Possible reasons include early anticipation of a difficult airway with adequate preparation prior to intubation, such as optimal jaw thrust with assistance, thus allowing better alignment of the airway for improved glottic view.

In our cohort, RSI was the most common method used during first intubation attempts (67.3\%), similar to the reported frequencies of RSI use in the US and Canada EDs. ${ }^{11}$ RSI is the preferred method in the $\mathrm{ED}^{3-5,11,22,23}$ predominantly due to the patient population. ED patients are often unfasted with a higher risk of aspiration, and RSI has been associated with high intubation success rates ${ }^{3,23-26}$ as it allows for reliable and rapid intubating conditions. In our institution, succinylcholine $(92.2 \%)$ is more commonly used as a paralytic agent for RSI than rocuronium (7.8\%). This is likely cultural as the use of neuromuscular blocking agents (NMBAs) in the multicentre NEAR project is roughly split evenly between rocuronium and succinylcholine. Historically, the majority of ED providers used succinylcholine as an NMBA due to its rapid onset of action, short duration of action and presence of fasciculations, allowing physicians to visually determine the onset of muscle paralysis. ${ }^{27}$ However, in several pathological states that upregulate muscle nicotinic acetylcholine receptors - such as direct muscle trauma, physical or chemical denervation, muscle relaxants or toxins and burns - the risk of succinylcholine-induced hyperkalemia is high. ${ }^{28}$

Recent studies demonstrating similar success rates in first-pass intubations between rocuronium and succinylcholine may prompt more usage of rocuronium at our institution for RSI in the future since rocuronium lacks the risk of hyperkalemia. ${ }^{10}$ Additionally, rocuronium has an excellent safety profile with the main (although rare) adverse effect, being allergy. ${ }^{27}$ Lastly, the initial concern of rocuronium's longer duration of action has been addressed with the introduction of a specific reversal agent, sugammadex..$^{29}$ This could alleviate ED 
physicians' concerns of prolonged respiratory paralysis when using rocuronium, in situations where repeated intubation attempts are unsuccessful.

In addition to achieving high first-attempt intubation success rates, we were also able to attain an adverse event rate of $13.8 \%$, which is lower than other institutions in Singapore $(23.2 \%)^{18}$ and comparable to the US centres $(12 \%) .^{3}$ Increasing intubation attempts prolongs the apnoeic time, resulting in higher rates of periintubation complications. ${ }^{7,8}$ This further reiterates the importance of improving first-pass success rates to limit the number of intubation attempts. In our institution, the use of the Vortex approach has also aided in limiting the number of attempts in rare occasions of intubation failures. The Vortex approach is an implementation template to guide practitioners in high-stake situations, ensuring that a maximum of 3 attempts of each technique-face mask, supraglottic airway and endotracheal intubation - is done, after which a "cannotintubate, cannot-oxygenate" rescue technique must be initiated. ${ }^{30}$ Inherent to our practice, appointed timekeepers help to read out aides, prompting operators when the next attempt in the Vortex approach is due. This prevents overzealous operators from persisting in intubation and prolonging hypoxia.

Of note, the majority of our patients received propofol $(53.1 \%, 355 / 669)$ and fentanyl $(40.1 \%, 268 / 669)$ as sedative agents post-intubation. This is similar to the entire NEAR cohort where $66 \%$ of those who received post-intubation sedation had propofol and $42.6 \%$ were given fentanyl infusion. ${ }^{31}$ Although propofol and fentanyl may cause haemodynamic instability, in our dataset, only $9.2 \%$ and $13.4 \%$ respectively were documented to be hypotensive within 15 minutes postintubation (information on post-intubation hypotension available in 446 patients). It is impossible to determine whether the choice of agent contributed to postintubation hypotension or if it was due to the underlying disease pathology.

The strength of our study lies in the prospective and real-time collection of variables during the intubation attempts, such as the predictors of a difficult airway that were properly assessed before the actual intubation. This allows for a more precise comparison on the accuracy of airway prediction in this study, by minimising recall bias and information loss, to preserve data integrity.

\section{Limitations}

Our study has its limitations. Firstly, this is a single-centre study and the results may not be generalisable to other institutions or patient cohort. Second, there were some predictors of a difficult airway that were not used during patient evaluation in our study. Examples include the relationship between maxillary and mandibular incisors, the presence of a prominent "overbite", neck length, and shape of palate..$^{32}$ Hence, we were not able to describe the prevalence and predictive value of these features in our patient cohort. Third, it is not routine clinical practice to weigh the patients before emergency intubation due to imminent need to secure the airway; thus, information collected regarding patients' habitus was assessed by visual estimation and clinicians' gestalt.

Fourth, although airway features were assessed prior to intubation, not all of the data collection forms were filled before the intubation attempts. In such cases where the data forms were filled after completion of intubation, impression of airway difficulty might be influenced by the glottic view and difficulty experienced during the attempt, which might have affected how intubators recorded their "gestalt" of difficulty. However, given the time-sensitive nature of this life-saving procedure, documenting this information prior to intubation was not always possible. Fifth, our study has a smaller sample size compared to other studies conducted on intubations in the ED. Nonetheless, the study provides a representation of ED-specific information on intubation and airway management. Lastly, the incidence of adverse events was too low for any meaningful association between operator experience, or choice of induction or paralytic agent to be established.

\section{CONCLUSION}

In our single-centre cohort, the majority of intubations were performed for medical indications by senior trainees or fellows utilising RSI and video laryngoscopy with good first-attempt success.

\section{REFERENCES}

1. Wong E, Ng YY. The difficult airway in the emergency department. Int J Emerg Med 2008;1:107-11.

2. Rao BK, Singh VK, Ray S, et al. Airway management in trauma. Indian J Crit Care Med 2004;8:98-105.

3. Walls RM, Brown CA, Bair AE, et al. Emergency airway management: a multi-center report of 8937 emergency department intubations. J Emerg Med 2011;41:347-54.

4. Sakles JC, Laurin EG, Rantapaa AA, et al. Airway management in the emergency department: A one-year study of 610 tracheal intubations. Ann Emerg Med 1998;31:325-32.

5. Simpson J, Munro PT, Graham CA. Rapid sequence intubation in the emergency department: 5 year trends. Emerg Med J 2006;23:54-6.

6. Mort TC. Emergency tracheal intubation: complications associated with repeated laryngoscopic attempts. Anesth Analg 2004;99:607-13. 
7. Sakles JC, Chiu S, Mosier J, et al. The importance of first pass success when performing orotracheal intubation in the emergency department. Acad Emerg Med 2013;20:71-8.

8. Ono Y, Kakamu T, Kikuchi H, et al. Expert-performed endotracheal intubation-related complications in trauma patients: incidence, possible risk factors, and outcomes in the prehospital setting and emergency department. Emerg Med Int 2018:5649476.

9. April MD, Schauer SG, Brown Rd CA, et al. A 12-month descriptive analysis of emergency intubations at Brooke Army Medical Center: a National Emergency Airway Registry study. US Army Med Dep J 2018;98-104.

10. April MD, Arana A, Pallin DJ, et al. Emergency department intubation success with succinylcholine versus rocuronium: a National Emergency Airway Registry study. Ann Emerg Med 2018;72:645-53.

11. Sagarin MJ, Barton ED, Chng YM, et al. Airway management by US and Canadian emergency medicine residents: A multicenter analysis of more than 6,000 endotracheal intubation attempts. Ann Emerg Med 2005;46:328-36

12. Low S, Chin MC, Deurenberg-Yap M. Review on epidemic of obesity. Ann Acad Med Sing 2009;38:57-9.

13. Seidell JC, Halberstadt J. The global burden of obesity and the challenges of prevention. Ann Nutr Metab 2015;66:7-12

14. Platts-Mills TF, Campagne D, Chinnock B, et al. A comparison of GlideScope video laryngoscopy versus direct laryngoscopy intubation in the emergency department. Acad Emerg Med 2009; $16: 866-71$

15. Yakushiji H, Goto T, Shirasaka W, et al. Associations of obesity with tracheal intubation success on first attempt and adverse events in the emergency department: An analysis of the multicenter prospective observational study in Japan. PLoS One 2018; $13 ; \mathrm{e} 0195938$.

16. Grant P, Newcombe M. Emergency management of the morbidly obese. Emerg Med Australas 2004; 16:309-17.

17. Juvin P, Lavaut E, Dupont H, et al. Difficult tracheal intubation is more common in obese than in lean patients. Anesth Analg 2003;97:595-600

18. Wong E, Fong YT. Trauma airway experience by emergency physicians. Eur J Emerg Med 2003;10:209-12.

19. Malhotra R, Bautista MAC, Müller AM, et al. The aging of a young nation: population aging in Singapore. Gerontologist 2019;59:401-10.
20. Johnson KN, Botros DB, Groban L, et al. Anatomic and physiopathologic changes affecting the airway of the elderly patient: implications for geriatric-focused airway management. Clin Interv Aging 2015;10:1925-34.

21. Kovacs G, Sowers N. Airway management in trauma. Emerg Med Clin North Am 2018;36:61-84.

22. Tayal VS, Riggs RW, Marx JA, et al. Rapid-sequence intubation at an emergency medicine residency: success rate and adverse events during a two-year period. Acad Emerg Med 1999;6:31-7.

23. Brown CA, Bair AE, Pallin DJ, et al. Techniques, success, and adverse events of emergency department adult intubations. Ann Emerg Med 2015;65:363-70.e1.

24. Kovacs G, Law JA, Ross J, et al. Acute airway management in the emergency department by non-anesthesiologists. Can J Anaesth 2004;51:174-80

25. Okubo M, Gibo K, Hagiwara Y, et al. The effectiveness of rapid sequence intubation (RSI) versus non-RSI in emergency department: an analysis of multicenter prospective observational study. Int $\mathrm{J}$ Emerg Med 2017;10:1.

26. Kim C, Kang HG, Lim $\mathrm{TH}$, et al. What factors affect the success rate of the first attempt at endotracheal intubation in emergency departments? Emerg Med J 2013;30:888-92.

27. Tran DTT, Newton EK, Mount VAH, et al. Rocuronium vs. succinylcholine for rapid sequence intubation: a Cochrane systematic review. Anaesthesia 2017;72:765-77.

28. Martyn JA, Richtsfeld M. Succinylcholine-induced hyperkalemia in acquired pathologic states. Anesthesiology 2006;104:158-69.

29. Chambers D, Paulden M, Paton F, et al. Sugammadex for the reversal of muscle relaxation in general anaesthesia: a systematic review and economic assessment. Health Technol Assess 2010;14:1-211.

30. Chrimes N. The Vortex: a universal 'high-acuity implementation tool' for emergency airway management. Br J Anaesth 2016;117 Suppl 1:i20-7.

31. Lembersky O, Golz D, Kramer C, et al. Factors associated with post-intubation sedation after emergency department intubation: a report from the National Emergency Airway Registry. Am J Emerg Med 2020;38:466-70.

32. Levine AI, DeMaria SJ. An updated report by the American Society of Anesthesiologists task force on management of the difficult airway: where is the aspiration risk assessment? Anesthesiology 2013;119:731-2 